\title{
Avaliação das vantagens da realização de enxerto autógeno em pré-maxila
}

\author{
Evaluation of the advantages of autogenous graft premaxilla
}

Evaluación de las ventajas de la realización de injerto autógeno en pre-maxila

Felipe Augusto Rosa dos Reis ${ }^{1 *}$, Halison Pereira Matiais ${ }^{1}$, Letícia Maria de Souza Ribeiro ${ }^{1}$, Pamela
Aparecida Diniz ${ }^{1}$, Márcio Américo Dias ${ }^{1}$.

\section{RESUMO}

Objetivo: Este trabalho visa abordar as vantagens de realização de enxertos através de osso autógeno. Métodos: Trata-se de um estudo analítico e descritivo de revisão bibliográfica, realizado por meio de pesquisas em artigos e monografias indexados nas bases científicas: Scielo, Pubmed, Bireme entre os anos de 2003 a 2017. Resultados: Segundo a literatura, o enxerto autógeno é classificado como padrão ouro por suas características singulares não encontradas em nenhum outro material, sendo elas: osteogênese, osteocondução e osteoindução. Ainda reúne vantagens como a baixa ocorrência de infecção, não apresenta rejeição por parte do leito receptor, menor custo, maior previsibilidade e baixa potencialidade de reabsorção apresentando-se a melhor terapêutica clínica e biológica. No entanto, uma grande desvantagem ainda presente é a necessidade de uma área doadora, as quais mais comuns são a sínfise mentoniana, o ramo da mandíbula, a tuberosidade da maxila, a calota craniana, a crista ilíaca, a costela, a tíbia e a fíbula. Conclusão: Como visto na literatura, o biomaterial que reúne maiores características ideais de um enxerto é o autógeno, e diante das revisões bibliográficas foi encontrado sucesso e proservação dos casos com o protocolo clínico do mesmo.

Palavras-chave: Enxerto autógeno, Osso autógeno, Osteoindução.

\begin{abstract}
Objective: This study aims to address the advantages of performing grafts through autogenous bone. Methods: This is an analytical and descriptive study of bibliographic review, carried out through research on articles and monographs indexed in the scientific bases: Scielo, Pubmed, Bireme between the years 2003 to 2017. Results: According to the literature, or autogenous graft it is classified as a gold standard because of its unique characteristics not found in any other material: osteogenesis, osteoconduction and osteoinduction. It still has advantages like the low occurrence of infection does not present rejection by the recipient bed, lower cost, greater predictability and low reabsorption potential presenting the best clinical and biological therapy. However, a major disadvantage still present is the need for a donor area, the most common of which are the mental symphysis, mandible branch, maxillary tuberosity, skull cap, iliac crest, rib, tibia and fibula. Conclusion: As seen in the literature, the biomaterial that has the greatest ideal characteristics of a graft is the autogenous one, and in front of the bibliographical revisions was found success and proservation of the cases with the clinical protocol of the same one.
\end{abstract}

Key words: Autogenous graft, Autogenous bone, Osteoinduction.

${ }^{1}$ Instituto Nacional de Ensino Superior e Pós Graduação Padre Gervásio (INAPÓS), Pouso Alegre-MG. *Email: felipereis7@hotmail.com

SUBMETIDO EM: 8/2018 


\section{RESUMEN}

Objetivo: Este trabajo pretende abordar las ventajas de la realización de injertos a través de hueso autógeno. Métodos: Se trata de un estudio analítico y descriptivo de revisión bibliográfica, realizado por medio de investigaciones en artículos y monografías indexados en las bases científicas: Scielo, Pubmed, Bireme entre los años de 2003 a 2017. Resultados: Según la literatura el injerto autógeno se clasifica como patrón oro por sus características singulares no encontradas en ningún otro material, siendo ellas: osteogénesis, osteoconducción y osteoinducción. Aún reúne ventajas como: la baja ocurrencia de infección, no presenta rechazo por parte del lecho receptor, menor costo, mayor previsibilidad y baja potencialidad de reabsorción presentándose la mejor terapéutica clínica y biológica. Sin embargo, una gran desventaja todavía presente es la necesidad de un área donante, las cuales más comunes son la sínfisis mentoniana, la rama de la mandíbula, la tuberosidad de la mandíbula, la calota craneal, la cresta ilíaca, la costilla, la tibia y la peroné. Conclusión: Como se ve en la literatura, el biomaterial que reúne mayores características ideales de un injerto es el autógeno, y ante las revisiones bibliográficas fue encontrado éxito y proservación de los casos con el protocolo clínico del mismo.

Palabras clave: Injerto autógeno, Hueso autógeno, Osteoinducción.

\section{INTRODUÇÃo}

O osso é um tecido complexo e vascularizado, que passa por diversos processos no decorrer da vida. Inicia-se com o crescimento e maturação, que após completada, um processo de reabsorção fisiológica iniciase. No entanto, com a perda precoce de dentes, infecções, más oclusões, traumatismos, distribuição inadequada de forças entre outros, trazem essa reabsorção antecipadamente. A ausência de osso nos rebordos alveolares tem sido uma grande questão na reabilitação estético-funcional em pacientes edêntulos, além de poder gerar danos à saúde tais como: incapacidade mastigatória, disfunção fonética, má nutrição, afora a insatisfação estética facial gerando distúrbios sociais e/ou psicológicos (THOMAZI GASSEN H, et al., 2008; FARDIN AC, et al., 2010; SILVA NETO JC, et al., 2010; MILHOMEM MLA, et al., 2014).

A busca por resolução na reabilitação oral, é tema de várias pesquisas e descrições de técnicas, as quais objetivam melhorar cada vez mais o resultado, resolvendo queixas como o comprometimento estético, deficiência mastigatória, desconforto pelo o uso de próteses removíveis, dentre outras. Diante disso, e com a vinda da Implantodontia moderna, o enxerto em bloco vem sido utilizado, na reformação de esqueleto ósseo, pois concernente a Implantodontia, a inexistência de esqueleto ósseo, atua diretamente no êxito protético (KLASSMANN FA, et al., 2006; MAIOR BSS, et al., 2003).

As comprovações científicas revelam que o enxerto autógeno se mostra o mais adequado no que se refere a neoformação óssea, sendo estimado como "padrão ouro", porém, ainda existem fatores que inviabilizam a sua utilização (KLASSMANN FA, et al., 2006; PINTO JGS, et al., 2007; PICCINELLI LB, et al., 2009).

$\mathrm{Na}$ tentativa de aprimorar o sucesso do tratamento com enxertos, foram desenvolvidos diversos materiais sintéticos, sendo classificados basicamente como: osteogênicos, osteoindutores e osteocondutores, sendo, osteogênicos, os materiais orgânicos com a capacidade de estimular a formação óssea a partir dos osteoblastos; osteoindutores, capazes de induzir a diferenciação celular em osteoblastos e condroblastos, gerando um aumento da formação óssea no sítio do enxerto; osteocondutores, são geralmente inorgânicos permitindo a formação de osso em sua superfície a partir de um tecido ósseo existente, onde utiliza células precursoras para a neoformação (FARDIN AC, et al., 2010).

Características como: osso disponível e ilimitado sem comprometimento da área doadora, promoção de formação óssea, ausência de reações imunológicas, revascularização rápida, estimular e promover a osteoindução e osteocondução e promover uma formação óssea adequada e semelhante ao tecido já existente, são ideais para os materiais utilizados nos enxertos (FARDIN AC, et al., 2010). 
Dito isto, dos materiais presentes na literatura, o que reúne a maior quantidade de características ideais é o osso autógeno, o qual é extraído do próprio paciente, no entanto, sua maior desvantagem é a necessidade de uma área doadora e grande trauma cirúrgico. As áreas doadoras são respectivamente: mento, túber, ramo mandibular, crista ilíaca e calota craniana, optados conforme a necessidade de tamanho do enxerto (PEREIRA JABD, et al., 2014). Este trabalho tem como objetivo abordar as vantagens de realização de enxertos através de osso autógeno.

\section{REVISÃO DE LITERATURA}

Como alternativa aos enxertos autógenos, têm-se os homógenos, sendo o osso retirado de indivíduos da mesma espécie, os heterógenos, sendo retirado osso de espécie diferente ao receptor e os aloplásticos são aqueles enxertos oriundos de material inorgânico ou sintético, sendo que, os homógenos foram bastante utilizados, no entanto, têm maior risco de transmissão de doenças e infecções (PEREIRA JABD, et al., 2014).

Diante da literatura o osso autógeno ainda se sobressai aos demais substitutos ósseos, trazendo as seguintes vantagens: presença de células vivas com capacidade osteogênica, ausência de reações imunológicas, menor grau de inflamação e infecção, ausência de risco de transmissão de patologias, reparação mais rápida, menor custo e de fácil obtenção (PINTO JGS, et al., 2007; RODOLFO LM, et al., 2017).

Após o procedimento, o enxerto se caracteriza por uma inflamação inicial e com a sua estabilização, têmse a formação de um coágulo e formação de tecido de granulação entre osso e enxerto. Em sequência a revascularização, os osteoblastos iniciam a secreção de matriz óssea e a osteoindução favorecida pela liberação de fatores de crescimento iniciam a neoformação e remodelação óssea. Já nos enxertos corticais é necessário a ação osteoclástica para criar caminho para a invasão de capilares e só então iniciar os processos de formação e remodelação (MATHIAS MVR, et al., 2003; KLASSMANN FA, et al., 2006; BORGES ANO, 2015).

Como indicações de enxertos se destacam os defeitos ósseos em altura e largura localizados e a determinação da qualidade óssea previamente a instalação de implantes, e como contraindicações se destacam: distúrbios psíquicos graves, usuários de drogas e álcool, doenças sistêmicas não controladas, quadros infecciosos na cavidade oral, crescimento ósseo em andamento, irradiação na área receptora a menos de 1 ano e fatores de risco como: diabetes mellitus, osteoporose, tabagismo e osteomalácia. Dessa forma, o cirurgião dentista deve estar atento aos princípios cirúrgicos, estado de saúde, bem como a classificação ASA e a solicitação de exames laboratoriais, antes do procedimento em questão (TODESCAN FF, et al., 2005).

\section{Áreas doadoras}

Os enxertos ósseos autógenos podem ser retirados de duas regiões extra orais e intra orais. Quando a área a ser reabilitada é de grande extensão as áreas doadoras extra orais são melhores indicadas, são estas: crista ilíaca, calota craniana, tíbia, fíbula e costela, sendo a crista ilíaca a mais comumente usada. Já se os sítios a serem reabilitados forem de pequena a média extensão, as áreas doadoras intraorais são os locais de eleição para o enxerto, são estas: sínfise mentoniana, ramo da mandíbula, tuberosidade da maxila. A região mentoniana se sobressai pelo fácil acesso ao leito e baixa mórbidade, contudo ramo da mandíbula oferece o melhor custo/benefício (FAVERANI LP, et al., 2014).

\section{Áreas doadoras intrabucais}

Mento: Região amplamente utilizada, sendo de fácil acesso, baixa morbidade, devendo ser respeitado limites para a remoção do bloco, sendo mínimo $6 \mathrm{~mm}$ anterior ao forame mentoniano, podendo envolver a borda da mandíbula bem como a linha média. Contudo cirurgião deve informar ao paciente que pode haver sensibilidade do tecido mole e pulpar, como também alterações no contorno do tecido mole da área mentoniana (NÓIA CF, et al., 2014). 
Corpo da mandíbula: Ideais para enxertos em região de molares inferiores, pois o paciente ficará com sítios cirúrgicos muito próximos, no entanto, essa região apresentam algumas falhas como: contaminação, deficiência em sutura bem como tensão do retalho, e riscos pertinentes à técnica como fratura do corpo e lesão dos nervos alveolar inferior e lingual (PEREIRA JABD, et al., 2014).

Tuberosidade: indicados para pequenas reconstruções e levantamento de seio maxilar, ainda possui medula vermelha, o que aumenta a neoformação. É uma área de fácil acesso, possui boa quantidade de osso esponjoso (PEREIRA JABD, et al., 2014).

\section{Áreas doadoras extra bucais}

Áreas como a crista ilíaca possui osso cortical e esponjoso e a calota craniana possui osso cortical, ambas regiões são indicadas para grandes reconstruções, no entanto, deve ser criteriosamente indicada, pois deve ser realizada sob anestesia geral em ambiente hospitalar com uma equipe multiprofissional, ainda ressaltando que o custo da técnica é muito elevado (PEREIRA JABD, et al., 2014).

\section{Técnica para remoção dos enxertos}

No tocante as técnicas para remoção de enxertos, estas são determinadas de acordo com a habilidade do cirurgião dentista, quantidade e qualidade óssea exigidas e localização do sítio doador (MILHOMEM MLA, et al., 2014).

\section{Técnica de fixação dos enxertos}

É necessário a adaptação do bloco de osso no local dos defeitos, realizando perfurações para permitir a vascularização e osteosíntese com parafusos e placas para a fixação do mesmo. Após este processo devese arredondar as bordas do bloco com brocas e reposicionar o retalho com uma correta técnica de sutura, afim de prevenir infecções e exposição da área receptora (PEREIRA JABD, et al., 2014).

É importante salientar o mecanismo de reparação dos enxertos, principalmente sobre a diferença entre o osso cortical e esponjoso: Os enxertos esponjosos devido sua maior vascularização, sofrem menos reabsorção se comparado aos enxertos corticais, oferecem estabilidade secundária e recuperam- se completamente. Os enxertos corticais oferecem estabilidade primária, pois apresentam maior densidade de matriz inorgânica, o qual participa da ancoragem dos implantes. Portanto os melhores resultados são obtidos em casos em que os enxertos são monocorticais e sua parte esponjosa disposta em contato ao leito receptor (CARDOSO AL, et al., 2007).

Dessa forma, a revascularização do osso esponjoso inicia-se poucas horas após o transplante, enquanto o osso cortical é revascularizado mais lentamente, no entanto em superfície encontra-se uma grande quantidade de proteínas morfogenéticas com grande capacidade indutora (PEREIRA JABD, et al., 2014).

\section{DISCUSSÃO}

Como visto na literatura o enxerto autógeno ainda é a melhor opção para reconstruções maxilomandibulares, sendo relatada como padrão ouro, decorrendo de vantagens como maior resistência a infecções, ausência de reações de corpo estranho, ainda a presença de células indutoras de osteogênese, permitindo um processo de reparação mais rápido e satisfatório, tendo como a principal desvantagem a necessidade de uma área doadora (JARDIM ECG, et al., 2009; PERREIRA CCS, et al., 2012).

Porém a necessidade de uma área doadora não é a única desvantagem, o mesmo também está limitado quanto a quantidade de material doador requerido. Sendo, pois de uma área de grande defasagem faz-se 
necessário intervir em uma cirurgia extra oral, o que gerará maior desconforto ao paciente, aumento significativo da morbidade. Devido a tamanho inconveniente que outros materiais sintéticos foram desenvolvidos com a finalidade de eliminar tais inconveniências (PINTO JGS, et al., 2007; JARDIM ECG, et al., 2009).

O enxerto homógeno é um bom material alternativo ao enxerto autógeno, pois possui potencialidade de remodelação e incorporação ao leito receptor, além de serem pre-moldados facilitando a adaptação ao leito receptor. Na utilização de enxerto homógeno pode-se ainda escolher as combinações estruturais, ou seja, se este será (cortical, medular, ou córtico-medular) podem também ser processados, liofilizado, desmineralizado (SOARES MVR, 2015).

Os enxertos aloplásticos são uma outra possibilidade de utilização nesta terapia, o qual vem ganhando espaço no mercado em virtude da fácil manipulação e baixa morbidade, por apresentarem em vários formatos e tamanhos. Além do tempo cirúrgico reduzido, por não necessitar de um segundo ato cirúrgico e área doadora. Tem por desvantagem, a possibilidade do leito receptor, o rejeitar o que levará a uma infecção, seguida de um segundo ato cirúrgico (SOARES MVR, 2015).

Outro biomaterial que pode ser utilizado como enxerto ósseo é o heterógeno constituído por compostos mineralizados de origem animal, mais comumente bovina. O qual possui propriedade osteocondutora. Este apresenta risco de contaminação a uma proteína bovina chamada príon. Esta patologia é conhecida vulgarmente como "doença da vaca louca" (SOARES MVR, 2015; RODOLFO LM, et al., 2017).

Contudo mesmo diante de tantas possibilidades, o enxerto autógeno é qualificado como sendo "padrão ouro", pois possui características histológicas, que estão associadas ao êxito dos enxertos ósseos são estas: osteogênese, osteocondução e osteoindução. Vão ainda além, as suas características, que o difere dos demais biomateriais, pois o mesmo possui também baixa ocorrência de infecção, não apresenta rejeição por parte do leito receptor, menor custo, maior previsibilidade e baixa potencialidade de reabsorção apresentandose a melhor terapêutica clínica e biológica. Vale salientar que, assim como os enxertos autógenos, os enxertos homógenos, heterógenos e aloplásticos possuem capacidade osteocondutora, porém as três propriedades biológicas, de osteocondução, osteoindução e osteogênese juntas, são peculiares somente ao enxerto autógeno (KLASSMANN FA, et al., 2006; MILHOMEM MLA, et al., 2008; JARDIM ECG, et al., 2009; PEREIRA JABD, et al., 2014; SOARES MVR, 2015; ROCHA ATM, et al., 2017; RODOLFO LM, et al, 2017).

\section{CONCLUSÃO}

O enxerto autógeno consiste ainda sendo o biomaterial "padrão ouro", pois nenhum outro biomaterial até então, conseguiu reunir todas as qualidades, que somente este possui. Além do sucesso proclamado pela literatura, dos casos em que foi utilizado.

\section{REFERÊNCIAS}

1. FARDIN AC, JARDIM ECG, PEREIRA FC et al. Enxerto ósseo em odontologia: revisão de literatura. Innovations Implant Journal, 2010; 5(3): 48-52.

2. SILVA NETO JC, PONTUAL AA, CARIBÉ PMV. Avaliação linear da espessura óssea da região mentual para enxertos ósseos intraorais. Revista de Cirurgia e Traumatologia Buco-maxilo-facial, 2010; 10(2): 77-82.

3. THOMAZI GASSEN H, MUNER FILHO R, MUNARI DE SIQUEIRA B et al. Reconstrução óssea de maxila atrófica utilizando enxerto de ramo mandibular. Stomatos, 2008; 14 (6):36-40.

4. MILHOMEM MLA. Enxertos autógenos intrabucais em implantodontia-revisão de literatura. AMAZÔNIA: SCIENCE \& HEALTH, 2014; 2 (3): 32-37 
5. MAIOR BSS, MAIOR HFS, OLIVEIRA RG. Enxerto ósseo autógeno em seio maxilar com implantes imediatos: uma alternativa terapêutica para maxilas atróficas. Estação Ciência 2003;1-9p.

6. PINTO JGS, CIPRANDI MTO, DE AGUIAR RC et al. Enxerto autógeno $x$ biomateriais no tratamento de fraturas e deformidades faciais-uma revisão de conceitos atuais. Revista da Faculdade de Odontologia-UPF, 2007; 12(3): 79-84.

7. PICCINELLI LB, ZARDO M, GONÇALVES RCG, et al. Estudo retrospectivo de 59 pacientes tratados com enxertos ósseos autógenos intrabucais e implantes dentais. Innov implant j, biomater esthet (Impr), 2009; 4 (3): 30-4.

8. AIS E. PROCEDIMENTOS CLÍNICOS. Enxertos ósseos autógenos de áreas doadoras intra-bucais e procedimentos clínicos integrados possibilitando reabilitação estética e funcional. RGO, 2006; 54 (4): 388-392.

9. PEREIRA JADB. Enxerto ósseo tipo autógeno em maxilares atróficos. (Monografia)- departamento de Odontologia da Universidade Federal de Santa Catarina, Florianópolis, 2014; 31 .

10. RODOLFO LM, MACHADO LG, BETONI-JÚNIOR W et al. Substitutos ósseos alógenos e xenógenos comparados ao enxerto autógeno: reações biológicas. Revista Brasileira Multidisciplinar, 2017; 20(1): 94-105.

11. BORGES ANO. Enxerto osso autógeno (Monografia): Vitória da Conquista: Faculdade Fascete,2014; 33p.

12. MATHIAS MVR; BASSANTA AD; RAMALHO AS et al. Enxerto autógeno com sítios doadores na cavidade oral. RGO (Porto Alegre), 2003; 51(4): 249-56.

13. TODESCAN FF, BECHELLI A, ROMANELLI H. Implantodontia Contemporânea: Cirurgia e Prótese. São Paulo: Editora Artes Medicas, 2005; 167p.

14. FAVERANI LP, FERREIRA GR, SANTOS PH et al. Técnicas cirúrgicas para a enxertia óssea dos maxilares revisão de Literatura. Rev. Col. Bras. Cir, 2014; 41(1): 061-067.

15. NÓIA CF, NÓIA CF, CHESSA JR et al. Considerações atuais sobre a remoção de enxerto do mento. Revista de Cirurgia e Traumatologia Buco-maxilo-facial, 2017; 14(1): 21-26.

16. CARDOSO ÁL, MAGALHÃES JCDA, ZAFFALON GTZ et al. Histologia e fisiologia do enxerto ósseo autógeno revisão de literatura. Innov implant j, biomater esthet (Impr), 2007; 2(3):10-13.

17. PERREIRA CCS, JARDIM ECG, CARVALHO ACGS et al. Técnica cirúrgica para obtenção de enxertos ósseos autógenos intrabucais em reconstruções maxilomandibulares. Rev bras cir traumatol buco-maxilo-fac, 2012; 15(2): 83-9.

18. JARDIM ECG, SANTOS PLD, JUNIOR S et al. Enxerto Ósseo em Odontologia. Revista Odontológica de Araçatuba, 2009; 30(2): 24-28.

19. SOARES MVR. Biomateriais utilizados na prática odontológica: uma revisão de literatura. (Monografia)- Curso de Odontologia da Universidade Estadual de Londrina, Londrina, 2015; 49 p.

20. ROCHA ATM, JÚNIOR ERT, SOUZA AS et al. Reconstrução maxilar utilizando enxerto pela técnica tunelização subperiosteal. Rev. Cir. Traumatol. Buco-Maxilo-Fac., Camaragibe, 2017; 17(4): 36-40. 